\title{
A Smart Skin PVC Foil Based on FBG Sensors for Monitoring Strain and Temperature
}

\author{
Alexandre Ferreira da Silva, Student Member, IEEE, Anselmo Filipe Gonçalves, Luís Alberto de Almeida Ferreira, \\ Francisco Manuel Moita Araújo, Paulo Mateus Mendes, Member, IEEE, and José Higino Correia, Member, IEEE
}

\begin{abstract}
Electronic products, including sensors, are often used in harsh environments. However, many parameters, such as severe weather conditions, high electronic noise, or dangerous chemical compounds in situ, may compromise the required high reliability. Therefore, development of a reliable sensing solution for monitoring those extreme conditions may become a very challenging task. This paper presents a smart skin foil developed to meet this specific need. Fiber Bragg grating sensors, one of the most reliable sensor solutions nowadays, were embedded in a thin foil made of polyvinyl chloride, giving rise to a smart structure with high durability and high resistance, and a dimensional stability above 99\%. In addition, the fabrication processes used are based on a technology that allows the development of large sensing areas. The sensing foil shows a linear stretching profile, with a slope of $7.8 \mathrm{~nm}$ per $1 \%$ elongation. After submitting the developed structure to temperature cycles, it revealed a thermal behavior of $0.1 \mathrm{~nm} /{ }^{\circ} \mathrm{C}$. Since the smart sensing structure was fabricated using available industrial fabrication processes, it is a feasible and ready-to-market solution.
\end{abstract}

Index Terms - Fiber Bragg grating (FBG), optical fiber sensors, sensor integration.

\section{INTRODUCTION}

$\mathbf{P}$ REVENTION of disasters caused by structure failures in harsh environments is a crucial issue, requiring the use of monitoring solutions that stand those environmental conditions [4]. Harsh environments are mainly characterized by extreme operation stress conditions, as mechanical, electrical, thermal, or chemical [5]. Possible events that lead to undesirable failures include cracks, corrosion, and temperature, among others. Reliable sensing devices are essential for structural monitoring as well as detecting any instability [6].

The sensing solution requirements are, for these cases, very tight since they need to overcome the surface topology, packaging, and system integration issues to withstand the surrounding environment [7].

Manuscript received September 30, 2009; revised February 5, 2010, April 22, 2010, and June 11, 2010; accepted June 23, 2010. Date of publication July 8, 2010; date of current version June 15, 2011.

A. Ferreira da Silva, P. M. Mendes, and J. H. Correia are with the Department of Industrial Electronics, University of Minho, 4800-058 Guimaraes, Portugal (e-mail: asilva@dei.uminho.pt; paulo.mendes@dei.uminho.pt; higino.correia@dei.uminho.pt).

A. F. Gonçalves is with TMG Automotive, 4800-490 Guimaraes, Portugal, and also with the Lycée Technique Du Centre, Luxemburg, Germany (e-mail: filipe.goncalves@tmgautomotive.pt).

L. A. de Almeida Ferreira and F. M. M. Araújo are with FiberSensing, 4470640 Maia, Portugal, and also with the Optoelectronics and Electronic Systems Unit, Institute for Systems and Computer Engineering of Porto (INESC Porto) (e-mail: luis.ferreira@ fibersensing.com; francisco.araujo@ fibersensing.com).

Color versions of one or more of the figures in this paper are available online at http://ieeexplore.iee.org.

Digital Object Identifier 10.1109/TIE.2010.2057233
The most common sensing solutions, both mechanic and electric-based sensors, that meet the sensing performance requirements are not able to stand specific environments, as high temperatures, electromagnetic noise, or chemical solutions in which they are in contact with [6], [8].

In recent years, optical sensors and, specifically, optical fiber sensors have been increasingly on focus due to performance and intrinsic characteristics [9], [10], e.g., optical fiber strain gages allow stress tests at a higher number of load cycles (fatigue behavior) than conventional sensors even with highstrain materials [11].

Optical sensors are suited solutions for difficult operating and environmental conditions, as electromagnetic stress, or in highly explosive atmospheres [10]. The ability to write several different strain gauges in a single glass fiber, leading to multiplexing, may be the simplicity enabling characteristic of the optical fiber technology-based sensing networks, since it avoids the required complex wiring of the standard sensors. Multiplexing, which allows a significant reduction on the number of connection leads, and the optical fiber sensors' light weight are responsible for the overall weight and system complexity reduction, in comparison to electrical strain gage systems. The overall optical fiber system (Table I) achieves high feasibility during its life cycle, using passive elements that do not represent any concern or risk to the environment in which they are applied. Nonetheless, one of the main drawbacks of optical fiber sensors is the required optical spectrometers of the sensor response readout. There is a wide range of readout devices with cost changing according to their resolution and sampling frequency. Resolutions of $1 \%$ of deformation and $0.1-^{\circ} \mathrm{C}$ temperature variation can be accomplished [2]

Due to the potential overall low cost, optical fiber sensing is being used to provide solutions in different application fields, such as biomedical [12], civil engineering [13], and aeronautics [14], among others. However, optical fiber sensors present some deployment challenges. First, optical fibers are difficult to handle, since they may easily break. In addition, there is a lack of reliable, fast, and economic solutions to assemble optical fiber sensors on the monitored structures. The common solutions adopted to attach fiber optic sensors to surfaces are based on epoxy resins [15] or even on welding methods [16], which do not ensure a good repeatability. A recent trend to overcome this issue relies on the development of sensor integration methods to place sensor inside the monitoring structure, resulting in the so-called fiber optic smart structures [17].

However, this is a difficult solution to implement, since, in many cases, sensor integration is required while the structure is 
TABLE I

SEnsor Type Comparison (The MONETARy Unit (\$) Is U.S. Dollar) [1]-[3]

\begin{tabular}{|c|c|c|}
\hline Type & Optical Fiber Sensor & Electro-Mechanical Sensor \\
\hline Strain Range & $10 \%$ & $3 \%$ \\
\hline Fatigue behavior & $\begin{array}{c}10^{7} \text { cycles without sensitivity and base } \\
\text { wavelength change }\end{array}$ & $\begin{array}{c}10^{7} \text { cycles with non-reversible change of base } \\
\text { value }\end{array}$ \\
\hline Temperature range & $\begin{array}{l}-270 \text { to } 900{ }^{\circ} \mathrm{C} \\
0 \text { to } 80{ }^{\circ} \mathrm{C} \text { without influencing the strain }\end{array}$ & $\begin{array}{l}-75 \text { to } 175^{\circ} \mathrm{C} \text { (for strain measurements) } \\
-40 \text { to } 70^{\circ} \mathrm{C} \text { (for temperature measurements) }\end{array}$ \\
\hline Limit of Detection & $1 \%$ strain; $0.1^{\circ} \mathrm{C}$ & $10 \%$ strain; $0.5^{\circ} \mathrm{C}$ \\
\hline Requirements & Optical Spectrum Analyzer and Light Source & Data Logger \\
\hline Expected Cost & $\begin{array}{c}\$ 50.00 / \text { sensor } \\
\sim \$ 5,000.00 / \text { Full Interrogation System } \\
\text { One reading system for all sensing network }\end{array}$ & $\begin{array}{c}\$ 25.00-\$ 40.00 / \text { sensor } \\
\sim \$ 1,000.00 / \text { Full Interrogation System } \\
\text { One reading system for each sensor }\end{array}$ \\
\hline
\end{tabular}

being fabricated. This is not possible for structures already on use and also a problem for new ones since the integration approach demands changes in the structure fabrication processes and materials, not feasible in the majority of the cases.

The alternative herein proposed and characterized consists in the fabrication of a skin layer that can be easily attached to the structure surfaces under monitoring. This solution provides an easier attachment method for optical fiber sensors to an already existing structure. The solution relies on the development of a methodology to embed optical fiber sensors on a flexible polyvinyl chloride (PVC) skin foil, using standard industrial fabrication processes. The output is a flexible and stretchable foil with a broad range of potential applications that includes structural health monitoring, automotive industry, aeronautics and aerospace, robotics, or even biomedical.

\section{SKIN-FoIL StRUCTURE}

In order to obtain a reliable flexible sensing material, the insertion of optical fiber sensors in the flexible foil must be achieved without compromising the sensor readout. In this way, if the sensor is designed to monitor strain or temperature, it is necessary to ensure a good bonding between the optical fiber and the flexible skin foil in which it is embedded. This guarantees a good transfer of strain or temperature from the host material to the sensor. Also important is the sensor application and long-term operation. In that perspective, the flexible polymeric substrate must provide, to optical fibers and sensors, protection against accidental damaging during handling, installation, and product life cycle in its environment, without disregarding sensitivity performance.

The solution that meets the skin-foil demands is based in the direct integration of optical fiber sensors inside the foil polymeric matrix. The strategy is to avoid the use of a specific substrate in which the optical fiber is first integrated, like a woven fabric, and then embedded in a polymeric matrix. If no intermediate substrate is used, it is possible to decrease the friction and risk of damaging the optical elements. In addition, a direct adhesion between the optical fiber and the skin-foil matrix improves the transfer of external stimuli from the host material to the sensor.

In order to keep the fiber in the midsection of the substrate, the prototypes were developed in a multilayer structure approach as shown in Fig. 1.

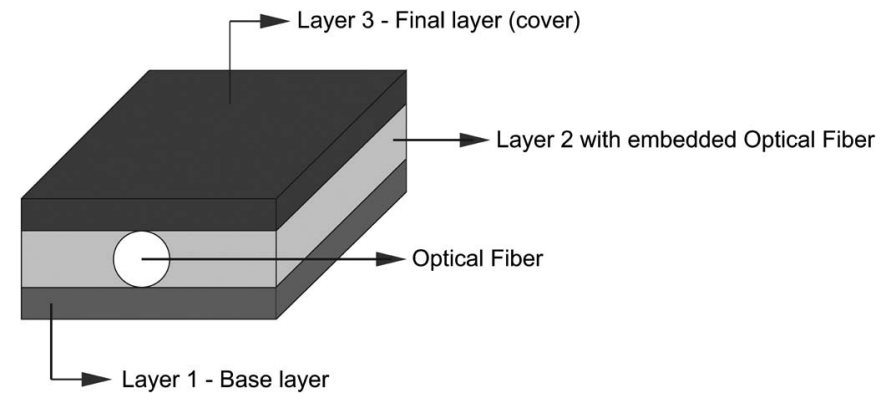

Fig. 1. Multilayer structure for embedded optical elements in flexible PVC foil.

The layer-by-layer construction allows the best yield in terms of fiber positioning consistency. In addition, this type of sandwiched configuration provides a more stable structure in terms of flexibility and resistance. Layers \#1 and \#3 play the role of a protective skin for the optical fiber, while layer $\# 2$ is responsible for the fiber adhesion to the carrier and for keeping it steady in its place.

\section{OpticAl Fiber SENSOR}

There is a large variety of optical fiber sensors used for monitoring purposes. Among such diversity, it is possible to find point sensors, where the sensing structure is placed in the fiber end, as Fabry-Pérot interferometers [18]; alternatively, the distributed sensors, if the spatial mode is discriminated, retrieving the measurand along the fiber length, as the Raman Brillouin scattering ones [19]; and finally, the quasi-distributed sensors, where the measurand is determined at particular and predefined points along the fiber, as the fiber Bragg gratings (FBGs) [20].

From this group of sensors, FBG sensors have caught attention in the last decade, due to their distinguishing advantages when compared with other sensors. First, they are not sensitive to the light source amplitude fluctuations, since the readout mechanism is based on wavelength instead of light intensity. Second, the Bragg structure is directly written into the fiber core, keeping the overall fiber structure unaffected. Third, it is a type of sensor that can be mass produced at a low cost, ensuring this way a competitive sensing solution. Finally, for quasidistributed sensing applications, the FBG-inherent multiplexing characteristic makes them a practical solution [21]. 


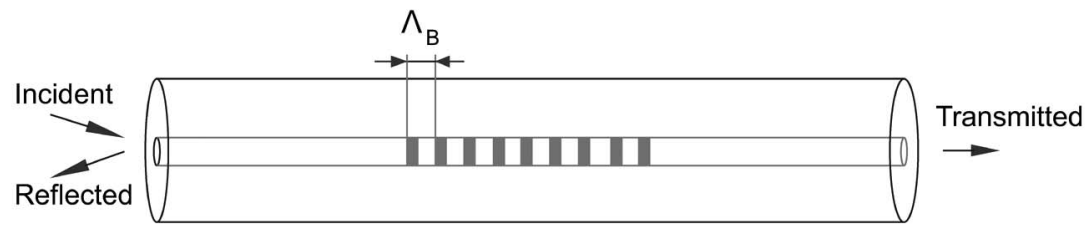

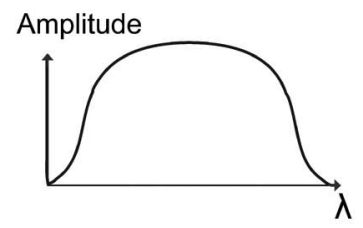

(a)

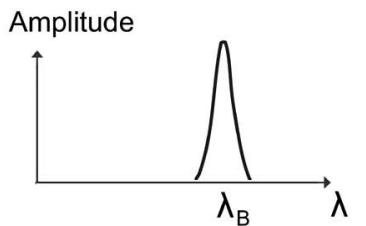

(b)

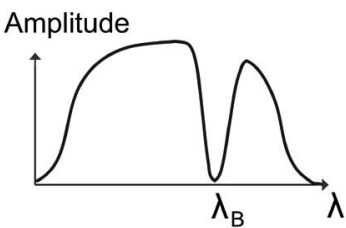

(c)

Fig. 2. Illustration of a Bragg sensor working principle. (a) Incident spectrum. (b) Reflected spectrum. (c) Transmitted spectrum.

The FGB is inscribed in optical fibers by forming a particular refractive index modification profile, leading to internal reflection of light. A fine band of the incident optical signal [Fig. 2(a)] is reflected [Fig. 2(b)] by the inscribed microstructure (gratings), resulting in a wavelength-specific resonance.

The FBG is produced by photo impression in photo-sensitive optical fibers with side exposure to patterned UV laser radiation. The beam pattern results from the phase mask that is usually placed between the UV source and the optical fiber (phase mask method). The mask is responsible for the grating structure and reflected wavelength. The remaining wavelengths will pass through the grating undisturbed, as shown in Fig. 2(c) [22].

Since the grating period $\left(\Lambda_{B}\right)$ is strain and temperature dependent, it becomes possible to measure these two parameters by analyzing the intensity of the reflected light as a function of the wavelength $\left(\lambda_{B}\right)$.

\section{SKIN-FoIL MATERIAL}

The foil material is a crucial element when considering its use for smart sensing structures. First, in terms of integration, it has to be able to keep the optical fiber in place and transfer the stimulus of the host structure with the minimum interference. On the other hand, the foil needs to ensure that it is able to resist the harsh conditions. Flexible skinlike foils that meet the previous requests can be made of a restricted group of different polymers.

Polyurethane may be among the safest choices with very long durability and high performance, regarding abrasion resistance and flexibility. However it has a downside, it is the most expensive skin [23], [24].

A polyolefin-based material is a suitable alternative for the required objective, but its performance related to softness, abrasion, and flexibility is, in general, more difficult to adjust [25], [26].

PVC was the final choice due to its performance/cost ratio. The PVC formulation is very flexible, allowing the customization of a skin layer for each specific application. Although plastics appear to be much alike in the daily use, PVC has an entire set of different features considering performance and functions [27]. Chemical stability is one of the major char-

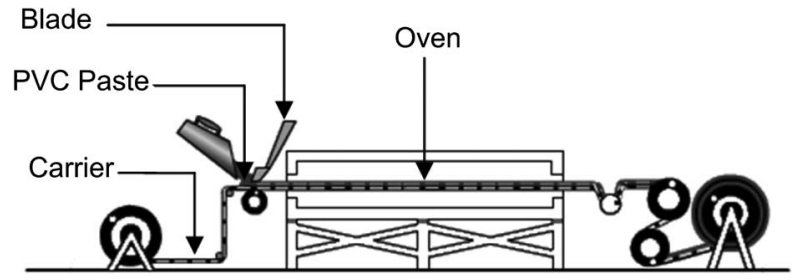

Fig. 3. Layout of industrial spread-coating process.

acteristics that results from its molecular structure. These are also characteristics of PVC resins, which, in addition, possess fire-retarding properties, robustness, chemical resistance, and mechanical stability, among other features [28].

\section{SMART SKIN-FoIL FABRICATION}

PVC has a wide range of processing techniques. Extrusion, calendering, and paste techniques (like spread coating, slush, and dip molding) are all PVC-enabled processing techniques.

Spread-coating technology allows the manufacture of foils for a broad range of applications, such as clothing, wall and floor coverings, conveyor belts, and wallpapers, among others [29].

The spread-coating technique runs continuously, and the polymeric structure is built layer by layer, with a carrier working initially as a support structure for the first layer.

The spread coating (Fig. 3) starts with a viscous paste being spread over a carrier. As the carrier passes beneath a steel blade, the layer thickness of a spread material is defined, and afterward, when going through the oven, the paste is cured, resulting in a solid and flexible layer. After that, the remaining layers are usually spread over the previous one. Several spreading and oven machines can be placed in series, enabling a multilayer structure. At the end, the final polymeric structure is detached from the carrier. This technique is the one that best enables the integration of optical fibers.

A Werner Mathis coating equipment was used for the production of a laboratory-scaled flexible skin foil with integrated optical fibers by the spread-coating process. This laboratory technique is the same as the one used in industrial process conditions, allowing industrial scale-up. 
TABLE II

SKIN-FOIL FABRICATION PROCEDURE

\begin{tabular}{llccc}
\hline Step & Operation & $\begin{array}{c}\text { Condition } \\
\text { Thickness } \\
{[\mu \mathrm{m}]}\end{array}$ & $\begin{array}{c}\text { Temp } \\
{\left[{ }^{\circ} \mathrm{C}\right]}\end{array}$ & $\begin{array}{c}\text { Heating } \\
\text { time }[\mathrm{s}]\end{array}$ \\
\hline 1 & Application of PVC-layer 1 & 200 & - & - \\
2 & Heat-curing of PVC-layer 1 & - & 200 & 60 \\
3 & Application of PVC-layer 2 & 300 & - & - \\
4 & Optical fibres insertion & - & - & - \\
5 & Heat-curing of PVC-layer 2 & - & 200 & 60 \\
6 & Application of PVC-layer 3 & 400 & - & - \\
7 & Heat-curing of PVC-layer 3 & - & 200 & 60 \\
8 & Cooling + manual release & - & - & - \\
\hline
\end{tabular}

In order to accomplish the structural layout shown in Fig. 1, layer \#1 is first spread over a paper carrier and cured. With a thickness of $200 \mu \mathrm{m}$, it is possible to achieve a flexible and light layer with minimum sensitivity loss.

For the middle layer, a thickness of $300 \mu \mathrm{m}$ was set to ensure the full wrap of the optical fiber, showing an external diameter of $250 \mu \mathrm{m}$. Since the final layer will be in contact with the environment, a 400- $\mu \mathrm{m}$ thickness was considered to be enough to guarantee optical fiber protection against the potential harsh conditions.

The temperature needed to secure a complete and successful cure of the polymer was $200{ }^{\circ} \mathrm{C}$ for a 60 -s period. As the fiber is able to sustain higher temperatures than $200^{\circ} \mathrm{C}$, the cure stage did not represent any constraint.

It is important to note that, for each application, the layer thickness can be tuned according to its end-use. More layers can even be added if high protection or damping effect is necessary. In addition, one of the layers can be made of a different material. It is the final application that defines the full properties of the structure layout. Table II synthesizes the smart sensing skin-foil fabrication procedure.

The chosen FBGs for the prototype fabrication were produced by FiberSensing. The gratings were written in hydrogenloaded standard fiber (Corning SMF 28e+) using the phase mask technique and a pulsed excimer laser. The length of the gratings is $8 \mathrm{~mm}$, and the resonance wavelength is $1541 \mathrm{~nm}$, corresponding to a refraction index modulation period of the core in the half-micrometer range $(\approx 0.52 \mu \mathrm{m})$, based on the effective refractive index of 1.47 .

\section{Structure Characterization}

Fig. 4 shows the developed smart sensing PVC skin foil. The foils present a high degree of flexibility, and the sensor is fully embedded. The foil surface was intact, and the fiber was not felt at the surface when touching the sample.

The smart skin foil cost alone was estimated to be around $\$ 30.00 / \mathrm{m}^{2}$. This value does not take into consideration the fiber and sensor cost, which has to be added at the end, since the smart foil can be fully customized in terms of fiber layout and sensor network size.

The samples underwent a dimensional stability test. This examination measured the linear dimensional change when the samples were exposed to temperature. In this case, two exposure scenarios were considered, one of $60 \mathrm{~min}$ for $80{ }^{\circ} \mathrm{C}$

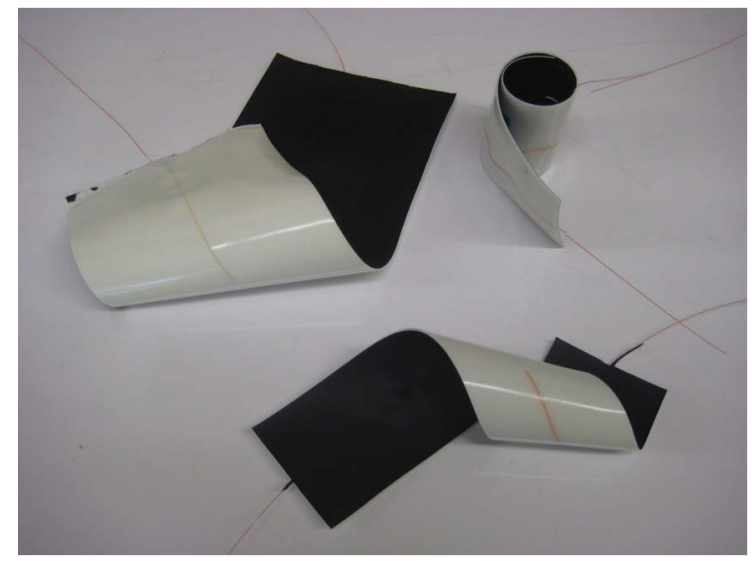

Fig. 4. Sensitive skin-foil prototypes.

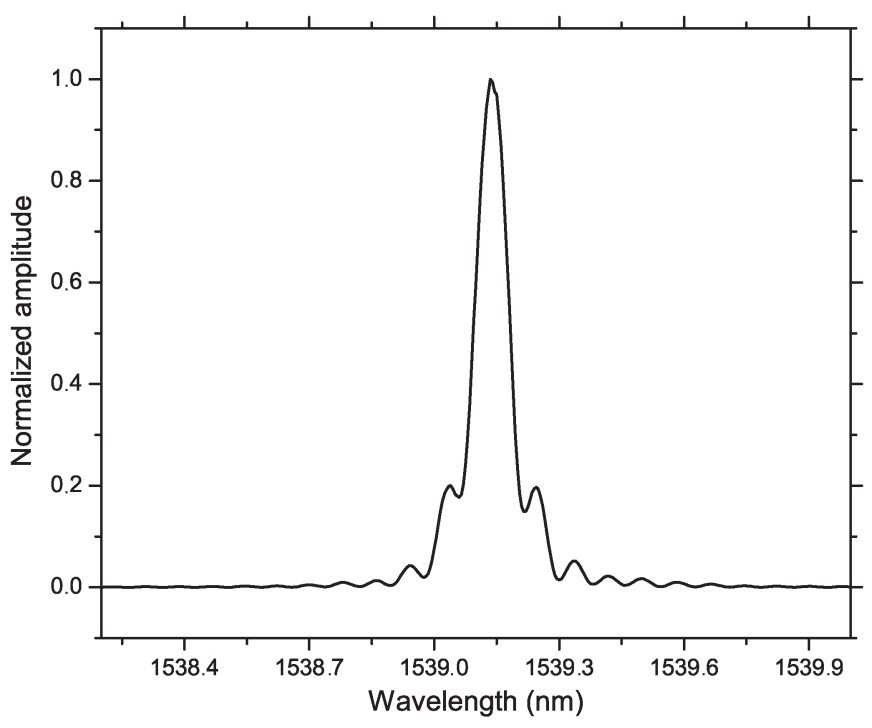

Fig. 5. Reflected spectrum from the FBG sensor.

and another one of $1 \mathrm{~min}$ for $190^{\circ} \mathrm{C}$. This test gave an indication of the sample stability in regard to internal stress introduced during the fabrication. The dimensional variation of the samples was lower than $1 \%$, which is in conformity with the PVC foil standards.

After the surface analysis and the successful integration, the optical response of the embedded sensor was evaluated. First, the spectrum signature of the FBG was read, using a FiberSensing BraggMETER 4200 unit. The obtained reflected spectrum is shown in Fig. 5. The FBG signature spectrum is well defined with a high signal-to-noise ratio.

The next step was to determine the sensor performance when subject to strain and temperature changes.

The strain characterization was obtained from samples placed in a tensile testing machine Instron 4302. In this test, the samples were stretched in a controlled manner, and the reflected optical signals from the Bragg structures, as well as the applied loads, were recorded. Fig. 6 shows the setup that was used for the mechanical tests. The samples were cropped in order to provide a $100 \times 50 \mathrm{~mm}^{2}$ area between grips (Fig. 7).

Two different tests were performed: Displacement was incremented at constant speed and in steps. 


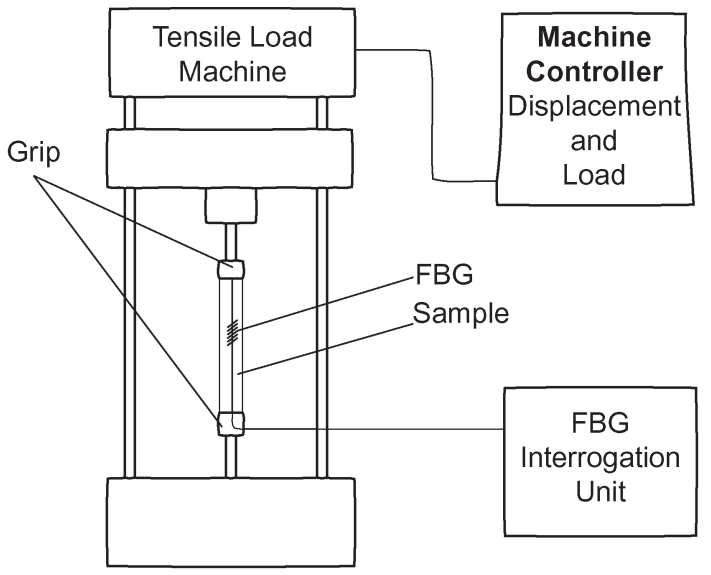

Fig. 6. Setup for strain tests.

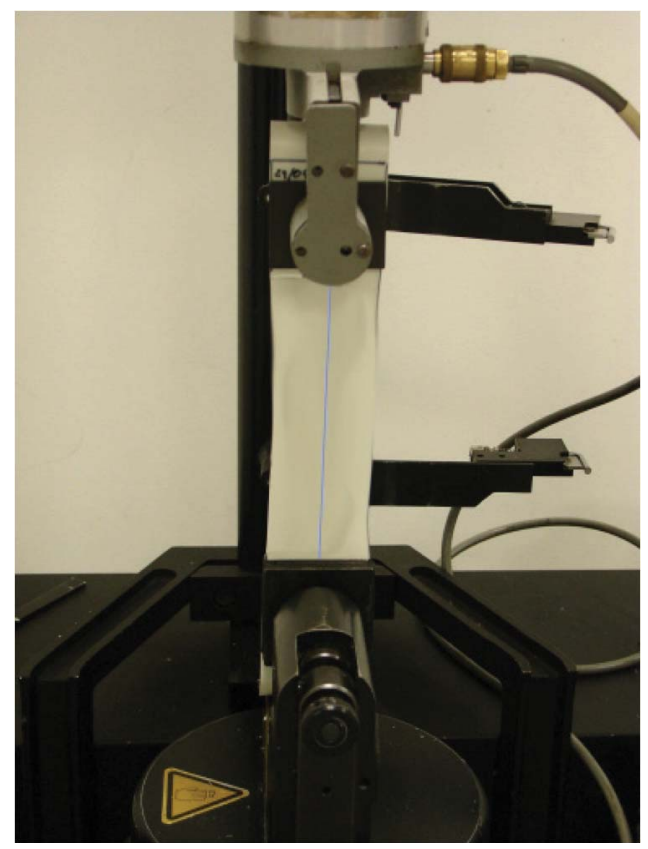

Fig. 7. Sample gripping in elongation-at-break test.

First, a constant displacement speed of $16 \mu \mathrm{m} / \mathrm{s}$ was applied to the smart foil. Fig. 8 shows the optical response of the sensor when subjected to this first test. Above $0.5 \%$ displacement, the sensor presents a linear optical response. Below that value, the sample reacted as nonlinear due to the initial stretch state of the sample. At the initial instant, the testing machine distance between the grips $(100 \mathrm{~mm})$ was higher than the effective length of the foil between the grips due to the foil flexibility. The sample presented a slope of $7.8 \mathrm{~nm}$ per $1 \%$ of elongation, for the sample with the fiber positioned axially. For this fiber layout, the samples were elongated up to $1.6 \%$. The system resolution will be dependent on the spectrum analyzer unit that is used since, as the sensor is a passive element, a small strain will always affect the fiber and a wavelength shift will result from that. In this way, it will be the interrogation unit ability to detect the wavelength change that defines the overall sensing sensitivity.

The elongation range, which is limited by the achievable elongation without breaking the fiber, can be improved with

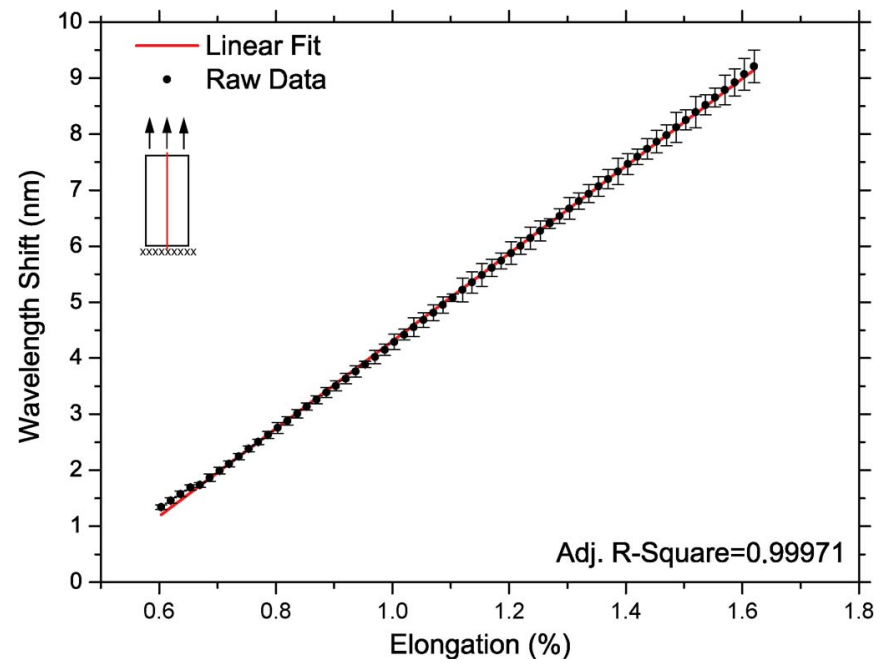

Fig. 8. Wavelength response to applied displacements at constant speed.

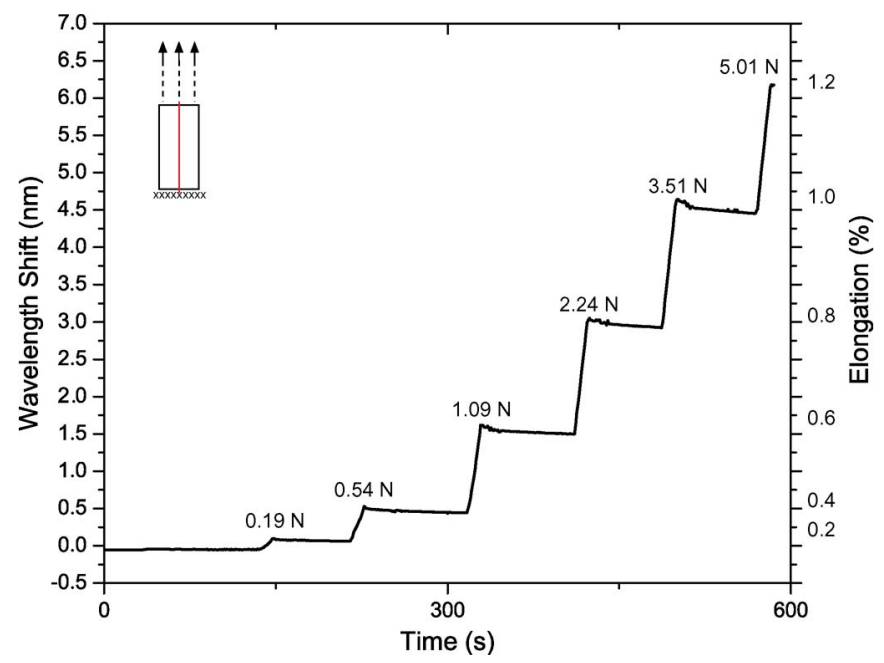

Fig. 9. Wavelength response to applied displacement by steps.

different fiber layouts. Since the manufacturing method enables the full customization of the fiber disposition, a different fiber layout can provide different elongation ranges.

In a second test, the displacement was applied in steps of $0.2 \%(200 \mu \mathrm{m})$ in order to evaluate the bonding between the optical fiber and the skin foil. The grip was kept at each elongation level for at least $1 \mathrm{~min}$ to assess the optical signal. The reflected wavelength component does not change while the grip is kept at the same elongation level, if a successful bond between the optical fiber and the polymeric foil is achieved.

Fig. 9 shows the structure response to this displacement step test. After stopping the grip in each step, a variation in the deviation of the signal is detected, but this is only due to the grip movement when stopping. After a few seconds, the optical signal is kept constant, proving a good bonding between the optical fiber and the polymeric structure.

The final test was performed to characterize the smart structure thermal behavior. The samples were glued to a metal plate, $0.8 \mathrm{~mm}$ thick, which was placed over a hot plate (Fig. 10). The heat source was programmed to achieve a temperature of $175^{\circ} \mathrm{C}$ at a rate of $1^{\circ} \mathrm{C}$ each $3 \mathrm{~s}$. 


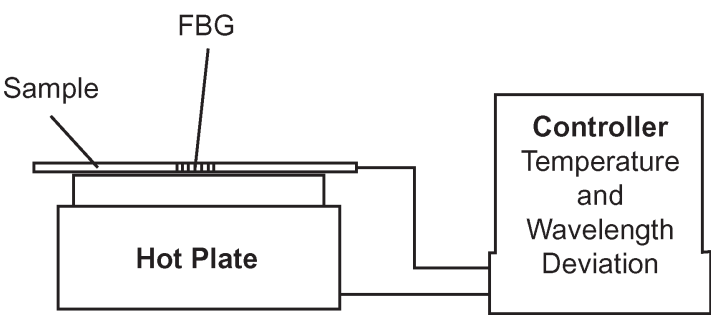

Fig. 10. Temperature test setup.

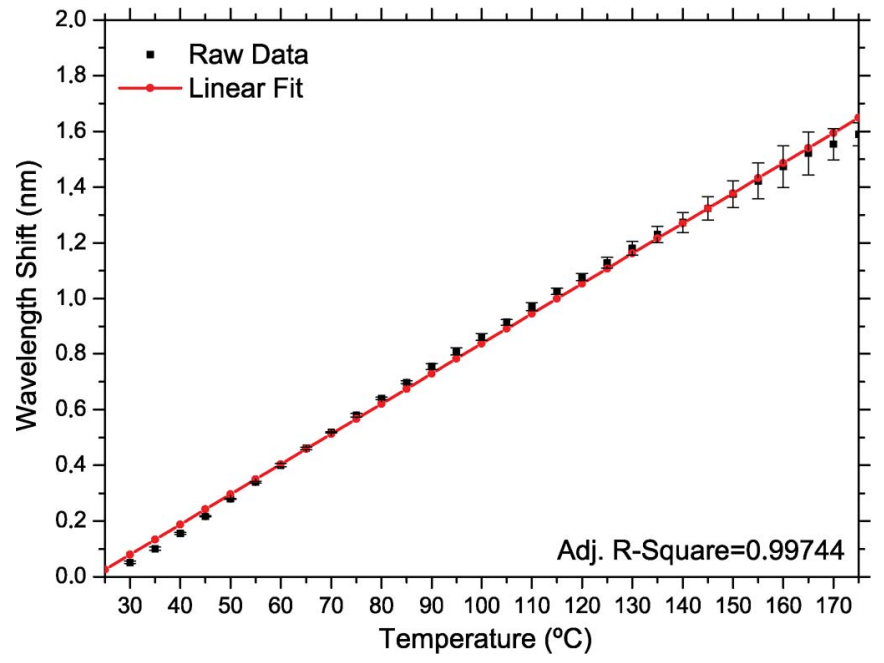

Fig. 11. Wavelength response to temperature changes.

As the metal plate, with the sensing foil attached to it, was being heated, the FBG wavelength shift was recorded, and the result is shown in Fig. 11. The temperature rising is followed by a positive deviation of the sensor reflected wavelength. The obtained data tend to follow a linear fit with an R-Square value of 0.99744 . The prototype responded to temperature changes with a slope of $0.1 \mathrm{~nm} /{ }^{\circ} \mathrm{C}$.

The previous analysis and results were obtained without simultaneous measurements of strain and temperature. However, in real application, it may not be likely to have such a perfect environment, particularly concerning harsh ones. Nevertheless, that situation can be solved with some approaches [30].

The simplest solution is to have several distinct FBGs, in which one of them is strain free, forcing it to be only sensitive to temperature changes. Thus, the temperature variation can be easily removed from the strain measurements. This approach, however, may raise some concerns with respect to the mechanical protection of the reference sensor, depending on the application, which is crucial for the present solution.

More interesting solutions for the integrated approach are the use of a high-pass filtering approach or readout with different fiber modes. The first approach allows retrieving fast strain vibrations and impacts from slowly varying environment temperature. The second one takes advantage of the different strain and temperature sensitivities of specific optical fiber, as the highly birefringent bow-tie-type optical fibers [31].

In chemical environments, the smart structure has the ability to withstand many compounds [32]. Basically, due to the PVCbased formulation, the sensing solution may be degraded, if in contact with sulfuric acid with a concentration above $98 \%$ or nitric acid with a concentration above 30\% [32]. These two chemical agents, at high concentrations, can gradually degrade the PVC foil by oxidation. Solvents are the other groups of compounds which are not compatible with the developed sensing solution [32]. The aggressive solvent tetra-hydro-furan can quickly dissolve the PVC foil at room temperature. PVC foils are a unique material that is able to withstand wide temperature cycles, UV radiation, humidity, and abrasion, among others, without having its structure affected.

\section{APPLICATIONS}

One of the main issues, concerning the optical fiber sensor use, is the in situ sensor deployment. In general, optical fibers are very fragile components when compared to other sensing technologies. Therefore, before mounting the optical fiber sensors to the host structure, the sensor is previously packaged on a metal box and then welded to the structure or directly glued to it, via epoxy resins. Such solutions are labor demanding, and it is difficult to ensure uniform application for all sensors.

The developed smart structure solution is able to overcome such issue. This integrated approach allows customized manufacture not only in terms of smart material size, in order to fit the final structure, but also in terms of fiber layout that can be embedded on the PVC foil. With this, a custom sensor network, in terms of sensor positioning and mechanical and thermal performance, can be designed for each specific application.

The developed smart structure can be compared to a thick $(900-\mu \mathrm{m})$ paper foil with the capability of sensing temperature, strain, and related measurands. It can be provided in a wound manner. In the application site, it is unwounded and applied as it was a wallpaper cover. In the aforementioned thermal test, a small A4-size smart foil was easily glued to a metal plate without any issue. This enables the covering of a full structure with a noncomplex sensing network due to the sensor's multiplexing characteristic. The interrogation of such network can be done from a far site from the sensing network by an optical fiber connection cable.

Automotive industry can use such smart solution to cover a vehicle cockpit with a sensing network that can provide real data about the structural state of the automobile structure, driver, and passengers, or it can even work as an interface between the driver and the vehicle systems.

In civil engineering, a mat based on this smart solution can be applied for structural health monitoring purposes, or even for new design ideas that require sensing systems. Bridges, tunnels, and buildings can have covered sections based on this solution.

The application field for the developed smart structure is enormous due to the manufacturing flexibility and its inherent properties.

\section{CONCLUSION}

A sensing solution for harsh environments has been developed. A PVC skin foil with integrated FBG sensors has proven to be a feasible solution for already existent and even new structures that need to be monitored for temperature, strain, and loads, among other related measurands. The choice of PVC, 
as the foil main material, provides enough protection for the majority of the ruthless environments. In addition, the selection of optical fiber sensors, particularly FBG-based sensors, allows the determination of the structure precise status with no associated risk.

The PVC skin foil was mainly characterized in terms of mechanical and thermal responses, since they are considered the two crucial parameters for this specific environment application. In terms of strain, it was possible to achieve a good bonding between the sensor and the foil, which allowed the sensor to track with success the applied displacement to the foil. A linear response of the sensor with a slope of $7.8 \mathrm{~nm}$ per $1 \%$ elongation emphasizes its performance. The thermal behavior was characterized with a linear response, shifting the reflected peak $0.1 \mathrm{~nm}$ per each $1-^{\circ} \mathrm{C}$ change. For both results, the optical deviation can always be directly correlated to each measurand.

The prototype performance and its inherent characteristics, allied with full customization capability, allow the smart structure to be targeted to a wide range of application fields, with few concerns in respect to harsh environments.

\section{REFERENCES}

[1] V. Micro-Measurements, Strain Gage Technology Technical Data. Malvern, PA: Vishay Intertechnology, Inc., 2009.

[2] B. Glisic and D. Inaudi, Fibre Optic Methods for Structural Health Monitoring. New York: Wiley, 2007.

[3] E. D. Loggers, User Guide_-Technical Escort Thermistor Sensors, 2009.

[4] C. F. R. Mateus and C. L. Barbosa, "Harsh environment temperature and strain sensor using tunable VCSEL and multiple fiber Bragg gratings," in Proc. SBMO/IEEE MTT-S IMOC, 2007, pp. 496-498.

[5] W. R. Fahrner and M. R. Werner, "Guest editorial special section on microsensors and microsystems in harsh environments," IEEE Trans. Ind. Electron., vol. 48, no. 2, pp. 247-248, Apr. 2001.

[6] K. Mine and Y. Morimoto, "Methods of alternating noise canceling for an instrumentation using strain gages," IEEE Trans. Ind. Electron., vol. 37, no. 3, pp. 250-252, Jul. 1990.

[7] R. Johnson et al., "Packaging technology for electronics applications in harsh, high temperature environments," IEEE Trans. Ind. Electron., vol. PP, p. 1-1, 2010.

[8] M. R. Werner and W. R. Fahrner, "Review on materials, microsensors, systems and devices for high-temperature and harsh-environment applications," IEEE Trans. Ind. Electron., vol. 48, no. 2, pp. 249-257, Apr. 2001.

[9] K. T. V. Grattan and T. Sun, "Fiber optic sensor technology: An overview," Sens. Actuators A, Phys., vol. 82, no. 1-3, pp. 40-61, May 2000.

[10] B. Lee, "Review of the present status of optical fiber sensors," Opt. Fiber Technol., vol. 9, no. 2, pp. 57-79, Apr. 2003.

[11] J. Sirkis, "Optical fiber strain sensing in engineering mechanics," in Photomechanics. New York: Springer-Verlag, 2000, pp. 233-272.

[12] G. Wehrle, P. Nohama, H. J. Kalinowski, P. I. Torres, and L. C. Guedes Valente, "A fibre optic Bragg grating strain sensor for monitoring ventilatory movements," Meas. Sci. Technol., vol. 12, no. 7, pp. 805-809, Jul. 2001.

[13] F. Ansari, Ed., Sensing Issues in Civil Structural Health Monitoring. New York: Springer-Verlag, 2005.

[14] E. J. Friebele, C. G. Askins, A. B. Bosse, A. D. Kersey, H. J. Patrick, W. R. Pogue, M. A. Putnam, W. R. Simon, F. A. Tasker, W. S. Vincent, and S. T. Vohra, "Optical fiber sensors for spacecraft applications," Smart Mater. Struct., vol. 8, no. 6, p. 813, Dec. 1999.

[15] H. F. Lima, R. da Silva Vicente, R. N. Nogueira, I. Abe, P. S. de Brito André, C. Fernandes, H. Rodrigues, H. Varum, H. J. Kalinowski, A. Costa, and J. de Lemos Pinto, "Structural health monitoring of the church of Santa Casa da Misericórdia of Aveiro using FBG sensors," IEEE Sensors J., vol. 8, no. 7, pp. 1236-1242, Jul. 2008.

[16] R. M. da Costa Marques Pimentel, M. C. B. Barbosa, N. M. S. Costa, D. R. F. Ribeiro, L. A. de Almeida Ferreira, F. M. M. Araújo, and R. A. B. Calçada, "Hybrid fiber-optic/electrical measurement system for characterization of railway traffic and its effects on a short span bridge," IEEE Sensors J., vol. 8, no. 7, pp. 1243-1249, Jul. 2008.
[17] B. Culshaw, "Optical fiber sensor technologies: Opportunities andperhaps-pitfalls," J. Lightw. Technol., vol. 22, no. 1, pp. 39-50, Jan. 2004.

[18] E. Canuto, F. Musso, and L. Massotti, "Automation and control of Fabry-Pérot interferometers," IEEE Trans. Ind. Electron., vol. 54, no. 2, pp. 848-857, Apr. 2007.

[19] G. Bolognini, M. A. Soto, and F. Di Pasquale, "Fiber-optic distributed sensor based on hybrid Raman and Brillouin scattering employing multiwavelength Fabry-Pérot lasers," IEEE Photon. Technol. Lett., vol. 21, no. 20, pp. 1523-1525, Oct. 2009.

[20] K. O. Hill and G. Meltz, "Fiber Bragg grating technology fundamentals and overview," J. Lightw. Technol., vol. 15, no. 8, pp. 1263-1276, Aug. 1997.

[21] Y.-J. Rao, "In-fibre Bragg grating sensors," Meas. Sci. Technol., vol. 8, no. 4, pp. 355-375, Apr. 1997.

[22] A. D. Kersey, M. A. Davis, H. J. Patrick, M. LeBlanc, K. P. Koo, C. G. Askins, M. A. Putnam, and E. J. Friebele, "Fiber grating sensors," J. Lightw. Technol., vol. 15, no. 8, pp. 1442-1463, Aug. 1997.

[23] M. Špírková, A. Strachota, M. Urbanová, J. Baldrian, J. Brus, M. Šlouf, A. Kuta, and Z. Hrdlièka, "Structural and surface properties of novel polyurethane films," Mater. Manuf. Process., vol. 24, no. 10/11, pp. 11851189, Oct. 2009.

[24] C. Hepburn, Polyurethane Elastomers, 2nd ed. London, U.K.: Elsevier, 1992.

[25] G. Collina, V. Braga, and F. Sartori, "New thermoplastic polyolefins elastomers from the novel Multicatalysts Reactor Granule Technology: Their relevant physical-mechanical properties after crosslinking," Polym. Bull., vol. 38, no. 6, pp. 701-705, Jun. 1997.

[26] G. Holden, H. Kricheldorf, and R. Quirk, Thermoplastic Elastomers, 3rd ed. Munich, Germany: Hanser, 2004.

[27] W. Associates, The Economic Benefits of Polyvinyl Chloride in the United States and Canada, 2009.

[28] PVC Fact Book, 2008.

[29] J. G. Bralla, Handbook of Manufacturing Processes-How Products, Components and Materials Are Made, 1st ed. New York: Industrial Press, 2007

[30] J. D. C. Jones, "Review of fibre sensor techniques for temperature-strain discrimination," in Proc. Opt. Fiber Sensors, 1997, pp. 36-39.

[31] L. A. Ferreira, F. M. Araujo, J. L. Santos, and F. Farahi, "Simultaneous measurement of strain and temperature using interferometrically interrogated fiber Bragg grating sensors," Opt. Eng., vol. 39, no. 8, pp. 22262234, Aug. 2000

[32] TELBAK Flexible PVC-Chemical Resistance Data, 2001.

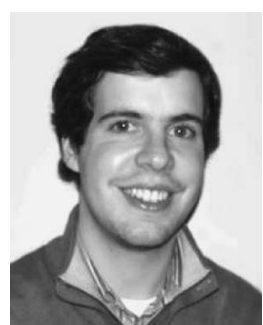

Alexandre Ferreira da Silva (S'10) received the Integrated Master degree in biomedical engineering, with specialization in medical electronics, from the University of Minho, Guimaraes, Portugal, in 2007, where he is currently working toward the Ph.D. degree in leaders for technical industries, over the MIT-Portugal Program in the engineering design and advanced manufacturing focus area.

Between 2006 and 2007, he spent six months at RWTH Aachen University, Aachen, Germany, studying alternative sputtering processes in order to evaluate their performance, justifying their utilization on electrode production. $\mathrm{He}$ is the author and coauthor of more than ten international communications and papers.

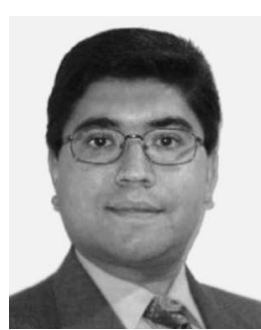

Anselmo Filipe Gonçalves received the B.S. degree in chemistry from the University of Kaiserslautern, Kaiserslautern, Germany, in 1998. In 2007, he attended the Advanced Study Course in technology management enterprise over the MIT-Portugal Program.

He is currently a Chemical Technician with the "Lycée Technique Du Centre," Luxemburg, Germany. He is also currently with TMG Automotive (a company of the Textile Group Têxtil Manuel Gonçalves), Guimaraes, Portugal, where he is responsible for innovation and research. His professional interests are in flexible polymer foil technology. 


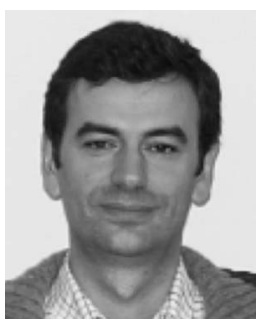

Luís Alberto de Almeida Ferreira received the Licentiate's degree in applied physics (optics and electronics), the M.Sc. degree in optoelectronics and lasers (white-light interferometry and signal processing in optical fiber sensors), and the Ph.D. degree in physics (in interrogation of fiber-optic Bragg grating sensors, after developing part of his research work in fiber-optic sensing with the Physics Department, University of North Carolina, Charlotte) from the University of Porto, Porto, Portugal, in 1991, 1995, and 2000 , respectively.

$\mathrm{He}$ is a Cofounder and currently the Engineering Manager of FiberSensing [a spin-off company of the Institute for Systems and Computer Engineering of Porto (INESC Porto)], Maia, Portugal, which develops, manufactures, and installs advanced monitoring systems based on fiber-optic sensing technology and addresses markets such as structural health monitoring in civil and geotechnical engineering, aerospace, and energy production and distribution. He is also currently a Senior Researcher with the Optoelectronics and Electronic Systems Unit, INESC Porto, where he develops his main R\&D activity in the areas of fiber-optic sensing and optical communications. He is the author and coauthor of more than 100 international communications, papers, and patents in the fields of fiber-optic sensing and fiber-optic communications.

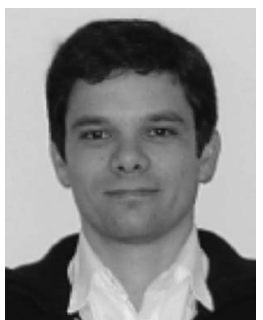

Francisco Manuel Moita Araújo received the Licentiate's degree in applied physics (optics and electronics) and the Ph.D. degree in physics (fiber Bragg gratings) from the University of Porto, Porto, Portugal, in 1993 and 2000, respectively.

$\mathrm{He}$ is a Cofounder and currently the Product Development Director of FiberSensing [a spin-off company of the Institute for Systems and Computer Engineering of Porto (INESC Porto)], Maia, Portugal, developing fiber-optic sensors and systems for different markets, such as structural health monitoring. He is also currently a Senior Researcher with the Optoelectronics and Electronic Systems Unit, INESC Porto. Previously, he was the Head of the Fiber Optic Technologies Unit, MultiWave Networks Portugal (a company that develops subsystems for fiber-optic communications), an Assistant Professor with the Physics Department, Faculty of Sciences, University of Porto, and a Senior Researcher with the Optoelectronics and Electronic Systems Unit where he developed research in the area of fiber-optic technologies from 1993 to 2001 . He is the author and coauthor of more than 100 international communications, papers, and patents in the fields of fiber-optic sensing and fiber-optic communications. His main activity research is related to optical communications and fiber-optic sensing.

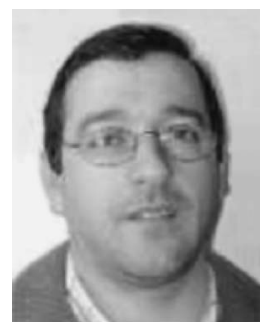

Paulo Mateus Mendes (M'05) received the B.Sc. and M.Sc. degrees in electrical engineering from the University of Coimbra, Coimbra, Portugal, in 1995 and 1999, respectively, and the Ph.D. degree in industrial electronics from the University of Minho, Guimarães, Portugal, in 2005.

From 1999 to 2005, he was a Lecturer with the Department of Industrial Electronics, University of Minho, where he has been an Assistant Professor since 2005 . He is currently involved in the research, at Algoritmi Center, on wafer-level chip-scale packaging for RF applications, wireless microsystems, antenna miniaturization, biomedical devices, and ambient assisted living technologies.

Dr. Mendes is a member of the IEEE Antennas and Propagation Society, IEEE Engineering in Medicine and Biology Society, and the European Microwave Association.

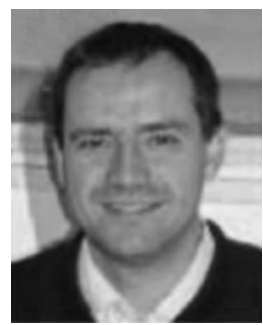

José Higino Correia (S'96-M'00) received the B.S. degree in physical engineering from the University of Coimbra, Coimbra, Portugal, in 1990 and the Ph.D. degree from the Laboratory for Electronic Instrumentation, Delft University of Technology, Delft, The Netherlands, in 1999, working in the field of microsystems for optical spectral analysis.

Currently, he is a full Professor with the Department of Industrial Electronics, University of Minho, Guimaraes, Portugal. His professional interests are in micromachining and microfabrication technology for mixed-mode systems, solid-state integrated sensors, microactuators, and microsystems.

Dr. Correia is a member of the IEEE Industrial Electronics Society. $\mathrm{He}$ was the General-Chairman of Eurosensors 2003 and MME 2007, Guimarães, Portugal. 